\title{
Association between perceived built environmental attributes and physical activity among adults in South Africa
}

\author{
Pasmore Malambo ${ }^{1 *}$, Andre P. Kengne ${ }^{2}$, Estelle V. Lambert ${ }^{3}$, Anniza De Villers ${ }^{2}$ and Thandi Puoane ${ }^{1}$
}

\begin{abstract}
Background: To investigate the association between perceived environmental attributes and leisure-time and transport-related physical activity.

Methods: This was a cross-sectional survey involving 671 South Africans aged $\geq 35$ years from urban and rural settings. International Physical Activity Questionnaire and Neighbourhood Walkability Scale were used to collect data. Multivariable logistic regressions were used to investigate the associations.

Results: Significant urban vs. rural differences were apparent in the distribution of most attributes of neighborhood environment. After adjusting for gender, age, setting and relevant interaction terms, proximity to local stores was significantly associated with leisure-time physical activity (OR: 4.26; $95 \% \mathrm{Cl}, 1.00-18.08)$; while proximity to transit stops $(2.44 ; 1.48-4.02)$, pleasant scenery $(1.93 ; 1.07-3.46)$, sidewalks $(2.36 ; 1.25-4.44)$, shade from trees $(2.14 ; 1.19-3$. 85), traffic $(2.17 ; 91.21-3.91)$ and well-lit streets $(2.01 ; 1.04-3.89)$ were significantly associated with walking for leisure. Four-way intersections $(4.54 ; 1.54-13.43)$, pleasant scenery $(3.84 ; 1.35-10.99)$, traffic $(0.28 ; 0.09-0.89)$, sidewalks (3.75; 1.06-13.27) and crosswalks were associated with transport related physical activity. Proximity to transit stops $(2.12 ; 1.17-3.84)$ and well maintained sidewalks $(2.69 ; 2.20-10.02)$ were significantly associated with total physical activity. Significant interactions by setting were apparent in some of the associations.

Conclusion: Some, but not all attributes of a neighborhood environment were significantly associated in expected directions with the three physical activity domains in this mixed urban and rural population. This study highlights the need for policy strategies aimed at improving or maintaining these perceived environmental attributes to promote physical activity.
\end{abstract}

Keywords: Physical activity, Built environment, Transport, Leisure, Walking, South Africa

\section{Background}

Regular physical activity (PA) is reported to be essential for the overall health and is associated with reduction in morbidity and mortality [1]. It is estimated that lack of physical activity accounts for between $3 \%$ and $4 \%$ of deaths among South Africans men and women respectively [2]. Consequently, 3.3\% of all deaths in South Africa in 2000 were attributed to physical inactivity [3]. Moreover, $48 \%$ of South African men and 63\% of African women were reported as being physically 'inactive' [4].

\footnotetext{
* Correspondence: pmalambo@hotmail.com

${ }^{1}$ Faculty of Community and Health Sciences School of Public Health,

University of Western Cape, Cape Town, South Africa

Full list of author information is available at the end of the article
}

Walking for transportation can assist people in meeting recommended levels of physical activity [1]. Accordingly, residents living in highly walkable neighborhoods are more likely to walk for leisure than those living in low-walkable neighborhoods [5]. These findings are supported by evidence from others studies that showed aesthetic environment, convenience of facilities for walking, accessibility, and perception about traffic and busy roads to be associated with walking [6].

There is a growing body of international data showing that perceived built environments are associated with physical activity $[7,8]$ at a population level. Perceived built environment features such as proximity to destinations, sidewalks, the presence of physically active people 
in the neighborhood, higher residential density, neighborhood safety [7] and aesthetic quality [9] have been associated with moderate to vigorous physical activity and walking. Similarly, access to services, streets connectivity, pedestrian infrastructures, heavy traffic and a mix of utilitarian and recreational destinations have been linked to active travel, recreational physical activity [8] and leisure-time physical activity and leisure-time walking [9].

The design of built environment attributes that shapes and promotes active living is vital in modern society as this helps town planners and policy makers to make decisions that could potentially improve physical activity at the neighborhood level [10]. However, there remains a gap in the literature concerning the association between perceived built environment attributes and physical activity in an African context. For instance, with a few exceptions [11], most studies in this field originate from high income countries [12]. Therefore, the aim of this study was to investigate the association between perceived environmental attributes and leisure-time and transport-related physical activity in urban and rural communities in South Africa.

\section{Methods}

\section{Study design}

This was a cross-sectional analysis of the baseline data of the South African arm of the Prospective Urban and Rural Epidemiology (PURE) Study collected in 2009.

\section{Study population and setting}

The study cohort included 2064 black South African men and women, aged 35-70 years, living in rural and urban sites, and was established in 2009. Communities selection purposefully favoured communities where a follow up of each respective cohort (urban vs rural) was feasible [13]. For the urban community (Langa in Cape Town), households were grouped into three development areas recognized administratively by the City of Cape Town Municipality. A street map obtained from the City of Cape Town was used to randomly select streets in each of these 3 areas. Once a street was selected, a systematic sampling of every second house was used to select potentially eligible participants for inclusion in the study. In the rural community (Mount Frere), the absence of delineated streets precluded following the same sampling approach used for the urban township. A cluster sample of houses in the community was therefore selected according to the division of areas determined by the clan heads. The inclusion criteria for both urban and rural were as follows: (1) households with a minimum of one member who was aged $35-70$ years, (2) houses situated within an identified neighborhood and (3) houses without occupants with a disability that precluded them from walking. The sampling yielded 437 households in the urban community (1061 individuals) and 329 households in the rural community (1003 individuals). All households with eligible individuals were approached for recruitment, by trained field workers. For this study, all members in each household who met the criteria were used for analysis.

\section{Data collection}

The PURE study used standardized, intervieweradministered questionnaires previously tested for anthropometric and biochemical measurements [13]. The study used the long version of the International Physical Activity Questionnaire (IPAQ) [14] and the Neighborhood Environment Walkability Scale (NEWS) questionnaire [15].

\section{Covariates}

Socio-demographic information on age, sex, marital status, education level, and occupation were elicited from participants using a self-administered questionnaire. Participant's age was grouped into 3 categories: 35- 44, 45-54, and 55 years or older. Marital status was classified as single, married, or divorced. Education level was classified as primary school education, secondary school education and tertiary school education. In this study, the occupation status was categorized as skilled (technicians, machine operators, clerks, skilled agriculture and fishery workers) and less skilled (homemaker, service, shop and market workers).

\section{Self-reported physical activity}

The long version of the IPAQ was used to collect data on self-reported physical activity [16].

The IPAQ long form questionnaire assesses physical activity across a comprehensive set of domains including leisure time, domestic and gardening (yard), workrelated, and transport-related physical activities, over the last 7 days. The IPAQ questionnaire was used to measure the frequency (days) and duration (in minutes) of vigorous-intensity PA, moderate-intensity PA, and walking-level PA separately. The total number of minutes per week in each PA category was computed (http://www.ipaq.ki.se). In the present study, four outcome variables were calculated: (1) leisure-time physical activity, (2) transport-related physical activity, (3) walking for leisure and (4) total physical activity. The four outcome variables were dichotomized into $<150 \mathrm{~min}$ and $\geq 150$ min according to WHO PA recommendations [17]. A 12-country, 14 - site study showed that the long IPAQ has excellent one-week test-retest reliability (pooled $r=0.81$ ) and acceptable validity (pooled $r=0.33$ ) when compared with accelerometer-measured physical activity [18]. 


\section{Self-perceived built environment}

Participants completed interviewer-administered NEWS questionnaires [19], which assess the perceived built environment on the following selected variables: land use mix-access (4 items), walking/cycling infrastructure (3 items), aesthetics (3 items), traffic (3 items) and crime (3 items). Participants were instructed to consider neighborhood as the area within a 15-20 min walk from their home. These items used 4-point Likert scale-type of responses ranging from strongly disagree (1) to strongly agree (4). For the purpose of statistical analysis, a dichotomous variable was constructed. Responses to items were collapsed into categories: "disagree" (strongly disagree and somewhat disagree) and "agree" (somewhat agree and strongly agree). The NEWS questionnaire has been shown to be reliable and valid in reflecting neighbourhood walkability and the perceived neighbourhood environment, across a broad range of countries and settings [19].

\section{Statistical analysis}

The starting sample comprised 1016 participants of whom 345 were excluded for unacceptable levels of missing data [20]. Therefore, the final analytic sample comprised 671 participants. We used SPSS ${ }^{\circ}$ version 22 for Windows (IBM Corp: Armonk New York) for all data analyses. Descriptive statistics were computed to measure frequencies for all categorical variables. In order to test for the association between perceived built environment and physical activity, univariable and multivariable models were constructed. In unadjusted logistic regression models, we tested the association between each perceived built environment item and the 4 physical activity outcomes. Potential confounders to be adjusted for in multivariable models, were first tested for their association with each of the outcome variables in univariable logistic regressions. These included age, sex, marital status, education and occupation. None of these variables were consistently associated with the 4 outcomes of interest (data not shown). Accordingly multivariable models were adjusted only for gender and age, under the assumption that confounding factor if any (both measured and unmeasured) would tend to be associated with either age or sex. In all regression models, all those who did not meet the 150 min per week recommended guidelines were used as reference category. In univariable models, the interactions between setting (urban vs. rural) and perceived built environment variables were tested by including in the same model the main effect of setting and built environment variable of interest, as well as their interaction term. Because of the many significant interactions, the interaction term of setting with each of the built environment variable was included in relevant multivariable models using the total sample. Furthermore, we have also presented the regression models stratified by setting. Statistical significance was set at $p<0.05$.

\section{Results}

Table 1 shows the descriptive characteristics of the sample. The sample included more women than men $(76 \%$ vs. $24 \%$ ) with no significance difference between urban

Table 1 Descriptive characteristic of individuals by location

\begin{tabular}{|c|c|c|c|c|}
\hline Variables (N (\%)) & Urban $=290$ & Rural = 381 & $p$-value & All $=671$ \\
\hline \multicolumn{5}{|l|}{ Covariates } \\
\hline Sex & & & 0.915 & \\
\hline Males & 69 (23.8) & $92(24.1)$ & & $161(24.0)$ \\
\hline Females & $221(76.2)$ & 289 (79.9) & & $510(76.0)$ \\
\hline Age & & & 0.303 & \\
\hline $35-44$ & $87(30.0)$ & $134(35.2)$ & & $221(32.9)$ \\
\hline $45-54$ & $100(34.5)$ & 129 (33.9) & & $229(34.1)$ \\
\hline $55+$ & $103(35.5)$ & 118 (31.0) & & $221(32.9)$ \\
\hline Marital status & & & 0.019 & \\
\hline Single & $132(45.5)$ & $133(34.9)$ & & 265 (39.5) \\
\hline Married & 106 (36.6) & $171(44.9)$ & & $277(41.3)$ \\
\hline Divorce & $52(17.9)$ & $77(20.2)$ & & $129(19.2)$ \\
\hline Education status & & & 0.165 & \\
\hline Primary & 86 (29.7) & $190(49.9)$ & & $276(41.1)$ \\
\hline Secondary & $186(64.1)$ & $179(47.0)$ & & $365(54.4)$ \\
\hline Tertiary & $18(6.2)$ & $12(3.1)$ & & $30(4.5)$ \\
\hline Occupation & & & 0.558 & \\
\hline Less skilled & $241(83.1)$ & $323(84.8)$ & & $564(84.1)$ \\
\hline Skilled & 49 (16.9) & $58(15.2)$ & & 107 (15.9) \\
\hline Ethnicity & & & 0.130 & \\
\hline Black African & $285(98.3)$ & 379 (99.5) & & $664(99.0)$ \\
\hline Colored & $5(1.7)$ & $2(0.5)$ & & $7(1.0)$ \\
\hline
\end{tabular}

Physical activity outcomes

Leisure-time physical activity $^{\mathrm{a}}$

$\begin{array}{ccccc}<150 \mathrm{~min} / \text { week } & 181(85.4) & 194(90.2) & & 375(87.8) \\ \geq 150 \mathrm{~min} / \text { week } & 31(14.6) & 21(9.8) & 52(12.2) \\ \text { Walking for leisure } & & & 0.095 & \\ <150 \mathrm{~min} / \text { week } & 153(53.3) & 226(59.8) & 379(57.0) \\ \geq 150 \mathrm{~min} / \text { week } & 134(46.7) & 152(40.2) & & 286(43.0) \\ \text { Transport-related physical } & & & \mathbf{0 . 0 1 8} & \\ \text { activity }^{\mathrm{a}} & & & & 454(88.3) \\ <150 \mathrm{~min} / \text { week } & 199(84.7) & 255(91.4) & & 60(11.7) \\ \geq 150 \mathrm{~min} / \text { week } & 36(15.3) & 24(8.6) & & \\ \text { Total physical activity } & & & <0.001 & \\ <150 \mathrm{~min} / \text { week } & 63(21.7) & 146(38.3) & & 209(31.1) \\ \geq 150 \mathrm{~min} / \text { week } & 227(78.3) & 235(61.7) & & 462(68.9)\end{array}$

${ }^{\text {a }}$ sub sample less than 671 due to missing variables Bold is significant $p$ value 
and rural areas $(p=0.915)$. Over $34 \%$ of the subjects were aged 45-54 years, similarly in urban and rural areas $(p=0.303)$. In all, $41.3 \%$ of the participants were married with significant urban vs. rural difference $(36.6 \%$ vs. $44.9 \%, p=0.019)$. Over $54.4 \%$ were educated to a secondary school level and only $15.9 \%$ had skilled jobs and majority were black Africans (99.0\%) from rural areas $(56.8 \%)$, with no rural vs. urban differences in these characteristics (all $\mathrm{p} \geq 0.130$; Table 1 ).

Only $12.2 \%$ of respondents met recommended physical activity guidelines $(\geq 150 \mathrm{~min} /$ week $)$ in the leisure-time domain. There was no difference in the prevalence of those persons accumulating at least $150 \mathrm{~min} /$ week of moderate-to-vigorous activity in leisure time, between urban and rural settings (14.6\% vs $9.8 \%, p=0.125)$. Overall, $57.0 \%$ of respondents did not accumulate at least 150 min per week of walking for leisure. This pattern was observed in both urban and rural settings (53.3\% vs 57.8\%), $p=0.095$ ). For transport-related physical activity, the proportion of respondents achieving at least 150 min per week was $11.7 \%$ in the overall sample, and $15.3 \%$ in urban and $8.6 \%$ in rural areas, respectively $(p=0.018)$. Altogether, $68.9 \%$ of the respondents met the global recommendations of at least $150 \mathrm{~min}$ of moderateto-vigorous physical activity per week (combining all domains), In fact, total moderate-to-vigorous activity prevalence was higher in the urban community (compared to the rural sample (78.3\% vs.61.7\%, $p<0.001$; Table 1 ).

Table 2 illustrates the attributes of built environment overall and by location. The majority of respondents (68\%) said they were able to do most of their shopping at a local store within walking distance from their homes. Destinations within neighborhoods were widely reported with more than $73 \%$ agreeing that there were many places to go within easy walking distance and $75 \%$ reporting that it was easy to walk to a transit stop from their residences. Approximately half the respondents (51\%) felt that the distance between intersections was short, 54\% agreed that there were many four-way intersections and $68 \%$ reported many alternative routes in their neighborhood. Despite over 54\% agreeing that there were sidewalks on most streets, $52 \%$ reported sidewalks were not well maintained and not separated by grass from the streets. Almost half of the respondents indicated that there were no trees and a lack of pleasant scenery (interesting things) to see while walking and neighborhood was full of litter. Although $53 \%$ of the respondents reported a high volume of traffic along their streets, over $64 \%$ reported low volumes of traffic along nearby streets. Approximately half (51\%) indicated that crosswalks did not help in crossing busy streets. The majority $(57.1 \%)$ of the respondents reported that streets in their neighborhood were poorly lit at night, with 52\% and $74 \%$ during the day/night respectively reporting that it was difficult to walk due to high crime rates (Table 2). In general, all built environment attributes were significantly different in urban and rural areas (all $p<0.001$; Table 2).

The univariable regression analyses in the overall sample are summarized in Table 3, showing some significant associations between built environment attributes and physical activity, but also a number of significant interactions, by setting, for those associations. In unadjusted regression analyses stratified by setting (Table 4), among urban dwellers who agreed that there were many fourway intersections, sidewalks were well maintained and separated from streets by grass and clean neighborhood were positively associated with leisure-time physical activity (all $p<0.05$ ), Table 4 . In addition, transit stop, four-way intersections, all infrastructure variables, pleasant scenery and well-lit streets at night were positively associated with walking for leisure (all $p<0.05$ ). This pattern was almost similar for total physical activity (Table 4). Meanwhile among rural counterparts, shade from trees and pleasant scenery were positively associated with leisure-time physical activity (both $p<0.05$ ). In addition, alternative routes and crosswalks were both associated with walking for leisure $(p<0.05)$. Those who agreed that streets were well maintained and separated from street by grass were more likely to participate in transport related physical activity (both $p<0.05$ ), Table 4 . Similarly, alternative routes in rural area were positively associated with total physical activity. Conversely, among urban respondents, high traffic volume and crime rate at night were inversely associated with walking for leisure (both $p<0.05$. Meanwhile in the rural area, high crime rate at night and traffic volume were negatively associated with leisure-time physical activity, walking for leisure and total physical activity (all $p<0.05$; Table 4 ), respectively.

The gender, age and site (and relevant interact terms in the overall sample) adjusted models are shown in Table 5 and 6. In these models applied to overall sample, significant associations were apparent between proximity to local stores and leisure time physical activity (4.26; 1.00 $18.08)$, proximity to transit stop and walking for leisure $(2.44 ; 1.48-4.02)$, proximity to transit stop and total physical activity $(2.12 ; 1.17-3.84)$, availability of four-way intersections and transport related physical activity $(4.54 ; 1.54-$ 13.43), interesting things and walking for leisure (1.93; 1.07-3.46), interesting things and transport related physical activity $(3.84 ; 1.35-10.93)$, and too much traffic along the street and leisure time related physical activity $(0.28$; 0.09-0.89). These associations were found in both urban and rural areas, although not always of the same magnitude, and not always statistically significant in each setting, separately (Table 6).

In the overall sample significant associations were also found between availability of sidewalks and walking for 
Table 2 Descriptive characteristics of built environment attributes by location

\begin{tabular}{|c|c|c|c|c|}
\hline Variables (N (\%)) & Urban $=290$ & Rural = 381 & $p$-value & All = 671 \\
\hline \multicolumn{5}{|l|}{ Environmental attributes } \\
\hline \multicolumn{5}{|l|}{ Land use mix-access } \\
\hline I can do most of my shopping at local stores & & & $<0.001$ & \\
\hline Agree & $243(83.8)$ & $218(57.2)$ & & $461(68.7)$ \\
\hline Disagree & $47(16.2)$ & $163(42.8)$ & & $210(31.3)$ \\
\hline Stores are within easy walking distance of my home & & & $<0.001$ & \\
\hline Agree & $243(83.8)$ & $218(57.2)$ & & $461(68.7)$ \\
\hline Disagree & $47(16.2)$ & $163(42.8)$ & & $210(31.3)$ \\
\hline $\begin{array}{l}\text { There are many places to go within easy walking distance } \\
\text { of my home }\end{array}$ & & & $<0.001$ & \\
\hline Agree & $258(89.0)$ & $237(62.2)$ & & $495(73.8)$ \\
\hline Disagree & $32(11.0)$ & $144(37.8)$ & & $176(26.2)$ \\
\hline It is easy to walk to a transit stop (bus, train) from my home & & & $<0.001$ & \\
\hline Agree & $258(89.0)$ & $249(65.4)$ & & $507(75.6)$ \\
\hline Disagree & $32(11.0)$ & $132(34.6)$ & & $164(24.4)$ \\
\hline \multicolumn{5}{|l|}{ Street connectivity } \\
\hline $\begin{array}{l}\text { The distance between intersections in my neighborhood is } \\
\text { usually short }\end{array}$ & & & $<0.001$ & \\
\hline Agree & $238(82.1)$ & $87(22.8)$ & & $325(48.4)$ \\
\hline Disagree & $52(17.9)$ & $294(77.2)$ & & $346(51.6)$ \\
\hline There are many four-way intersections in my neighborhood & & & $<0.001$ & \\
\hline Agree & $240(82.8)$ & $125(32.8)$ & & $365(54.4)$ \\
\hline Disagree & $50(17.2)$ & $256(67.2)$ & & $306(45.6)$ \\
\hline $\begin{array}{l}\text { There are many alternative routes for getting from place to } \\
\text { place in my neighborhood }\end{array}$ & & & $<0.001$ & \\
\hline Agree & $248(85.5)$ & $208(54.6)$ & & $456(68.0)$ \\
\hline Disagree & $42(14.5)$ & $173(45.4)$ & & $215(32.0)$ \\
\hline \multicolumn{5}{|l|}{ Places for walking and cycling } \\
\hline There are sidewalks on most of the streets in my neighborhood & & & $<0.001$ & \\
\hline Agree & $246(84.8)$ & $118(31.0)$ & & $364(54.2)$ \\
\hline Disagree & $44(15.2)$ & $263(69.0)$ & & $307(45.8)$ \\
\hline The sidewalks in my neighborhood are well maintained & & & $<0.001$ & \\
\hline Agree & $224(77.2)$ & $97(25.5)$ & & $321(47.8)$ \\
\hline Disagree & $66(22.8)$ & $284(74.5)$ & & $350(52.2)$ \\
\hline $\begin{array}{l}\text { There is a grass/dirt strip that separates the streets from the sidewalks in } \\
\text { my neighborhood }\end{array}$ & & & $<0.001$ & \\
\hline Agree & 199 (68.6) & $122(32.0)$ & & $321(47.8)$ \\
\hline Disagree & $91(31.4)$ & $259(68.0)$ & & $350(52.2)$ \\
\hline \multicolumn{5}{|l|}{ Neighborhood surroundings } \\
\hline Trees give shade for the sidewalks in my neighborhood. & & & $<0.001$ & \\
\hline Agree & 198 (68.3) & $114(29.9)$ & & 312 (46.6) \\
\hline Disagree & $92(31.7)$ & $267(70.1)$ & & 359 (53.5) \\
\hline $\begin{array}{l}\text { There are many interesting things to look at while walking in my } \\
\text { neighborhood. }\end{array}$ & & & $<0.001$ & \\
\hline Agree & $210(72.4)$ & $104(27.3)$ & & $314(46.8)$ \\
\hline Disagree & 80 (27.6) & $277(72.7)$ & & $357(53.2)$ \\
\hline
\end{tabular}


Table 2 Descriptive characteristics of built environment attributes by location (Continued)

\begin{tabular}{|c|c|c|c|c|}
\hline My neighborhood is generally free from litter. & & & $<0.001$ & \\
\hline Agree & $173(59.7)$ & $107(28.1)$ & & $280(41.7)$ \\
\hline Disagree & $117(40.3)$ & $274(71.9)$ & & $391(58.3)$ \\
\hline \multicolumn{5}{|l|}{ Safety from traffic } \\
\hline $\begin{array}{l}\text { There is so much traffic along the street I live such that it makes } \\
\text { it difficult to walk in my neighborhood }\end{array}$ & & & $<0.001$ & \\
\hline Agree & $235(81.0)$ & $127(33.3)$ & & $362(53.9)$ \\
\hline Disagree & $55(19.0)$ & $254(66.7)$ & & $309(46.1)$ \\
\hline $\begin{array}{l}\text { There is so much traffic along nearby streets that it makes it difficult } \\
\text { to walk in my neighborhood }\end{array}$ & & & $<0.001$ & \\
\hline Agree & $179(61.7)$ & $61(16.0)$ & & $240(35.8)$ \\
\hline Disagree & $111(38.3)$ & $320(84.0)$ & & $431(64.2)$ \\
\hline $\begin{array}{l}\text { The crosswalks in my neighborhood help walkers feel safe crossing } \\
\text { busy streets }\end{array}$ & & & $<0.001$ & \\
\hline Agree & 228 (78.6) & $98(25.7)$ & & $326(48.6)$ \\
\hline Disagree & $62(21.4)$ & $283(74.3)$ & & $345(51.4)$ \\
\hline \multicolumn{5}{|l|}{ Safety from crime } \\
\hline My neighborhood streets are well lit at night & & & $<0.001$ & \\
\hline Agree & $234(80.7)$ & $54(14.2)$ & & $288(42.9)$ \\
\hline Disagree & $56(19.3)$ & $327(85.8)$ & & $383(57.1)$ \\
\hline $\begin{array}{l}\text { The crime rate in my neighborhood makes it unsafe to go on walks } \\
\text { during the day }\end{array}$ & & & $<0.001$ & \\
\hline Agree & $22(76.2)$ & $133(34.9)$ & & 354 (52.8) \\
\hline Disagree & 69 (23.8) & $248(65.1)$ & & $317(47.2)$ \\
\hline $\begin{array}{l}\text { The crime rate in my neighborhood makes it unsafe to go on walks } \\
\text { at night }\end{array}$ & & & $<0.001$ & \\
\hline Agree & $243(83.8)$ & $257(67.5)$ & & $500(74.5)$ \\
\hline Disagree & $47(16.2)$ & $124(32.5)$ & & $171(25.5)$ \\
\hline
\end{tabular}

Bold is significant $p$ value

leisure $(2.36 ; 1.25-4.44)$, availability of sidewalks and transport related physical activity $(3.75 ; 1.06-13.27)$, availability of maintained sidewalks and total physical activity (4.69; 2.20-10.02), shaded (trees) sidewalks and walking for leisure $(2.14 ; 1.19-3.85)$, too much traffic along the street and walking for leisure (2.17; 91.21-3.91), crosswalks and transport related physical activity $(4.11 ; 1.47-11.50)$, and well lighted streets at night and walking for leisure (2.01; 1.04-3.89). When rural and urban settings were considered separately, these associations were not always in the same direction, not always significant, nor did that always result in significant interactions by setting (Table 6).

Finally, some significant associations were found in setting specific analyses, but not in the overall sample. These included the associations of leisure time physical activity with transit stops and crime rates in rural setting, the association of walking for leisure with availability of well-maintained sidewalks in urban setting, the associations of total physical activity with availability of four-way intersections, neighborhoods free from litter and well-lit streets at night in urban settings, and shaded sidewalks in rural setting (Table 6).

\section{Discussion}

A proportion of subjects reached 150-min per week threshold in total physical activity outcomes. After adjusting for gender, age and site (including interaction terms), attributes of the built environment including proximity to local stores, transit stops, four-way intersections, the availability of sidewalks and crosswalks, shade from trees and pleasant scenery, as well as a high volume of traffic, well-lit streets at night and concerns of personal safety during the day were associated with meeting physical activity guidelines of accumulating at least $150 \mathrm{~min}$ of moderate-to-vigorous activity per week, among the urban and rural South Africans surveyed.

This study supports the growing evidence that proximity and ease of access to destinations and services such as local stores and transit stops from residences are linked to more active living including [21] leisure-time 


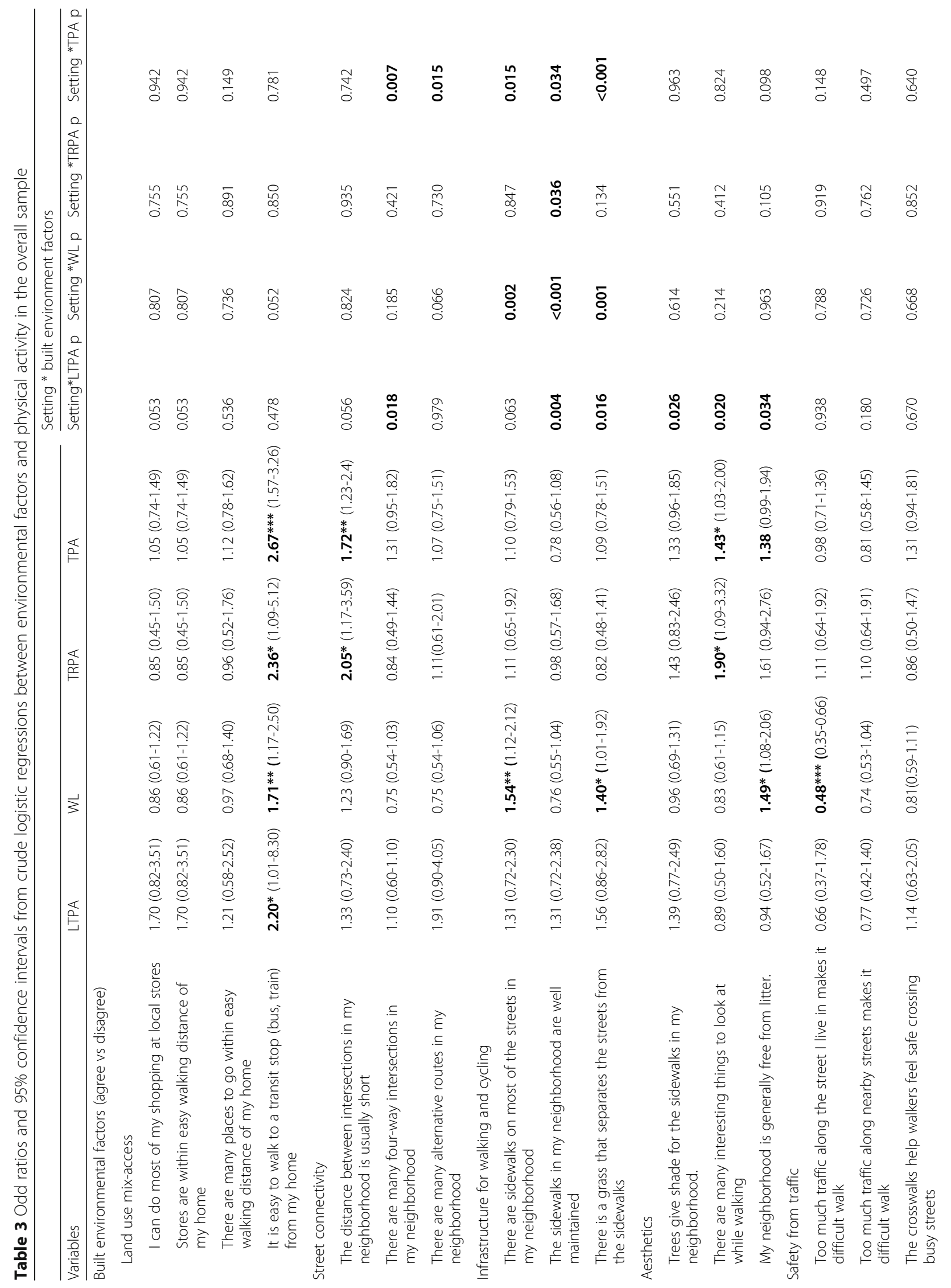




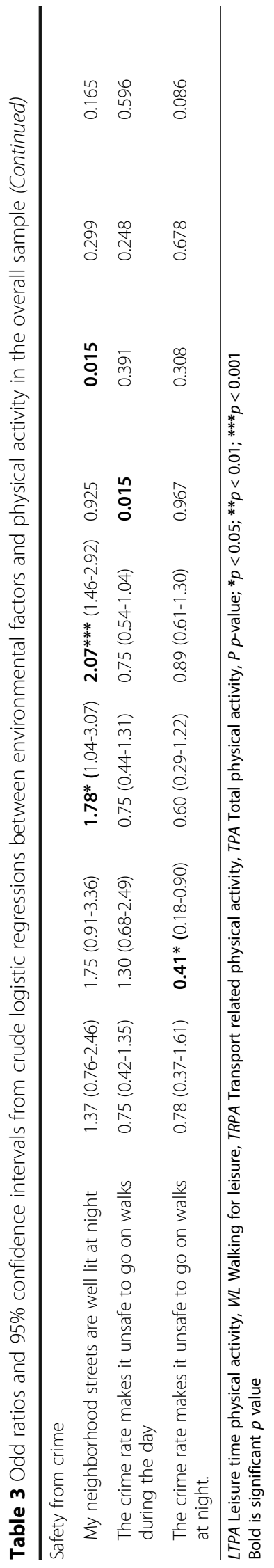




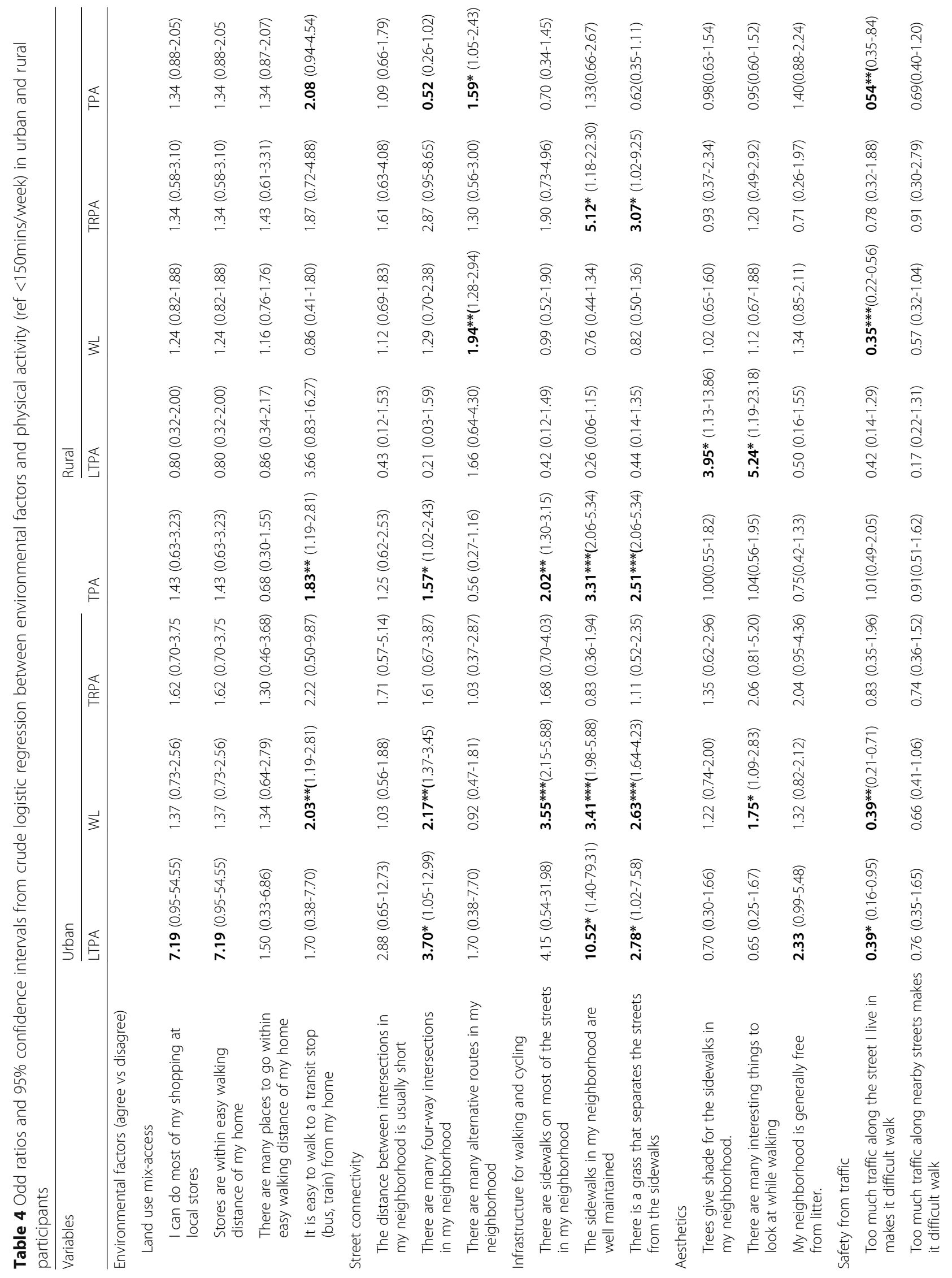




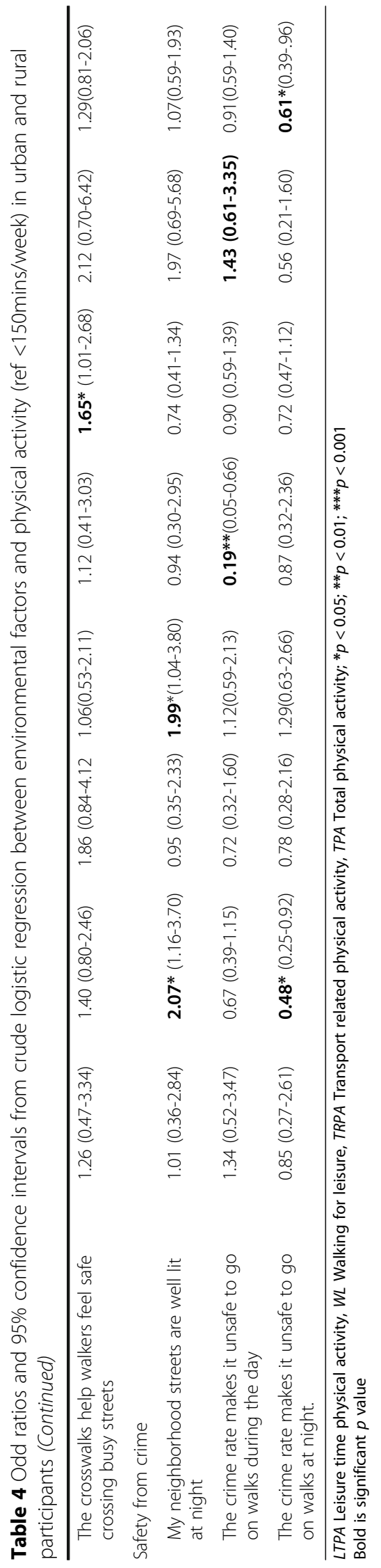


Table 5 Odd ratios and 95\% confidence intervals from adjusted logistic regression between environmental factors and physical activity in urban and rural participants in the overall sample

\begin{tabular}{|c|c|c|c|c|}
\hline \multirow[b]{2}{*}{ Variables $^{a}$} & \multicolumn{4}{|c|}{ Physical activity outcomes } \\
\hline & LTPA & WL & TRPA & TPA \\
\hline \multicolumn{5}{|l|}{ Environmental factors (agree vs disagree) } \\
\hline \multicolumn{5}{|l|}{ Land use mix-access } \\
\hline I can do most of my shopping at local stores & $4.26 *(1.00-18.06)$ & $1.38(0.76-2.51)$ & $0.87(0.35-2.16)$ & $0.73(0.39-1.38)$ \\
\hline $\begin{array}{l}\text { There are many places to go within easy walking } \\
\text { distance of my home }\end{array}$ & $0.46(0.14-1.84)$ & $1.01(0.54-1.90)$ & $0.81(0.27-2.46)$ & $0.93(0.46-1.87)$ \\
\hline $\begin{array}{l}\text { It is easy to walk to a transit stop (bus, train) from } \\
\text { my home }\end{array}$ & $3.72(0.85-16.28)$ & $\mathbf{2 . 4 4} * * *(1.48-4.02)$ & $2.58(0.77-.8 .66)$ & $\mathbf{2 . 1 2 *}(1.17-3.84)$ \\
\hline \multicolumn{5}{|l|}{ Street connectivity } \\
\hline $\begin{array}{l}\text { The distance between intersections in my neighborhood } \\
\text { is usually short }\end{array}$ & $1.01(0.27-3.80)$ & $1.45(0.75-2.80)$ & $3.53(0.96-12.91)$ & $0.68(0.34-1.38)$ \\
\hline There are many four-way intersections in my neighborhood & $0.85(0.22-3.21)$ & $0.59(0.31-1.14)$ & $4.54 *(1.54-13.43)$ & $1.85(0.93-3.65)$ \\
\hline There are many alternative routes in my neighborhood & $2.37(0.63-8.92)$ & $0.82(0.48-1.40)$ & $1.35(0.49-3.74)$ & $0.95(0.51-1.76)$ \\
\hline \multicolumn{5}{|l|}{ Infrastructure for walking and cycling } \\
\hline There are sidewalks on most of the streets in my neighborhood & $0.71(0.17-2.89)$ & $2.36^{* *}(1.25-4.44)$ & $3.75^{*}(1.06-13.27)$ & $1.13(0.56-2.27)$ \\
\hline The sidewalks in my neighborhood are well maintained & $0.52(0.15-1.81)$ & $1.12(0.55-2.27)$ & $0.58(0.19-1.73)$ & $4.69 * * *(2.20-10.02)$ \\
\hline There is a grass that separates the streets from the sidewalks & $1.85(0.71-4.85)$ & $0.83(0.45-1.54)$ & $0.96(0.42-2.23)$ & $1.30(0.74-2.28)$ \\
\hline \multicolumn{5}{|l|}{ Aesthetics } \\
\hline Trees give shade for the sidewalks in my neighborhood. & $1.07(0.37-3.05)$ & $\mathbf{2 . 1 4} *(1.19-3.85)$ & $1.02(0.38-2.78)$ & $1.11(0.59-2.09)$ \\
\hline There are many interesting things to look at while walking & $0.72(0.24-2.22)$ & $1.93 *(1.07-3.46)$ & 3.84*(1.35-10.93) & $0.92(0.49-1.73)$ \\
\hline My neighborhood is generally free from litter. & $1.50(0.65-3.45)$ & $1.34(0.85-2.11)$ & $1.56(0.75-3.23)$ & $1.04(0.64-1.68)$ \\
\hline \multicolumn{5}{|l|}{ Safety from traffic } \\
\hline Too much traffic along the street I live in makes it difficult walk & $\mathbf{0 . 2 8 *}(0.09-0.89)$ & $\mathbf{2 . 1 7 *}(1.21-3.91)$ & $0.76(0.28-2.06)$ & $0.93(0.50-1.74)$ \\
\hline Too much traffic along nearby streets makes it difficult walk & $1.28(0.46-3.58)$ & $1.05(0.54-2.03)$ & $0.89(0.36-2.23)$ & $0.90(0.49-1.66)$ \\
\hline The crosswalks help walkers feel safe crossing busy streets & $0.64(0.20-1.98)$ & $0.73(0.38-1.43)$ & $\mathbf{4 . 1 1} * *(1.47-11.50)$ & $1.08(0.56-2.07)$ \\
\hline \multicolumn{5}{|l|}{ Safety from crime } \\
\hline My neighborhood streets are well lit at night & $0.70(0.23-2.18)$ & $\mathbf{2 . 0 1} *(1.04-3.89)$ & $1.52(0.43-5.38)$ & $2.50(1.24-5.04)$ \\
\hline The crime rate makes it unsafe to go on walks during the day & $0.44(0.17-1.17)$ & $0.87(0.49-1.52)$ & $0.89(0.34-2.36)$ & $1.10(0.61-1.99)$ \\
\hline The crime rate makes it unsafe to go on walks at night. & $1.42(0.46-4.41)$ & $0.91(0.54-1.51)$ & $1.70(0.57-5.04)$ & $0.83(0.46-1.52$ \\
\hline
\end{tabular}

LTPA Leisure time physical activity, WL Walking for leisure, TRPA Transport related physical activity, TPA Total physical activity; ${ }^{a}$ adjusted for age, sex, site and the interaction term of site with each of the predictors of interest; ${ }^{*} p<0.05 ;{ }^{* *} p<0.01 ;{ }^{* * *} p<0.001$ Bold is significant $p$ value

physical activity, walking for leisure and total physical activity. These results are aligned with the results from an 11-country, International Physical Activity and Environment Network study [22]. Similarly, a study in China found access to physical activity destinations were related to leisure-time physical activity [9]. Access to services has been associated with sufficient walking in some studies [23] but not all [24]. Although the current study did not ask the participants about ownership of cars, it is unlikely that many people owned one, and thus walking for transport is their only means of travel [25].

We found that the occurrence of short distances between intersections and 4-way intersections in the neighborhood was significantly associated with respondents achieving 150 min or more of transport-related physical activity. This mirrors outcomes in most existing studies [6], with one exception [26]. The latter study, however, was confined to the university environment and consequently their perception of street connectivity may have been different from other studies [26]. Nevertheless, similar to other studies, the possible interpretation for a positive association would be that the availability of well-connected streets provides direct routes and safety for commuters, which ultimately increases the opportunity to walk. In a South African context, and particularly in urban areas where most of the streets are tarred and well connected, it facilitates residents' use of streets for transport related physical activity.

Similar to existing studies [27], we also found that the presence of sidewalks on most streets was positively associated with walking for leisure. Likewise, better- 


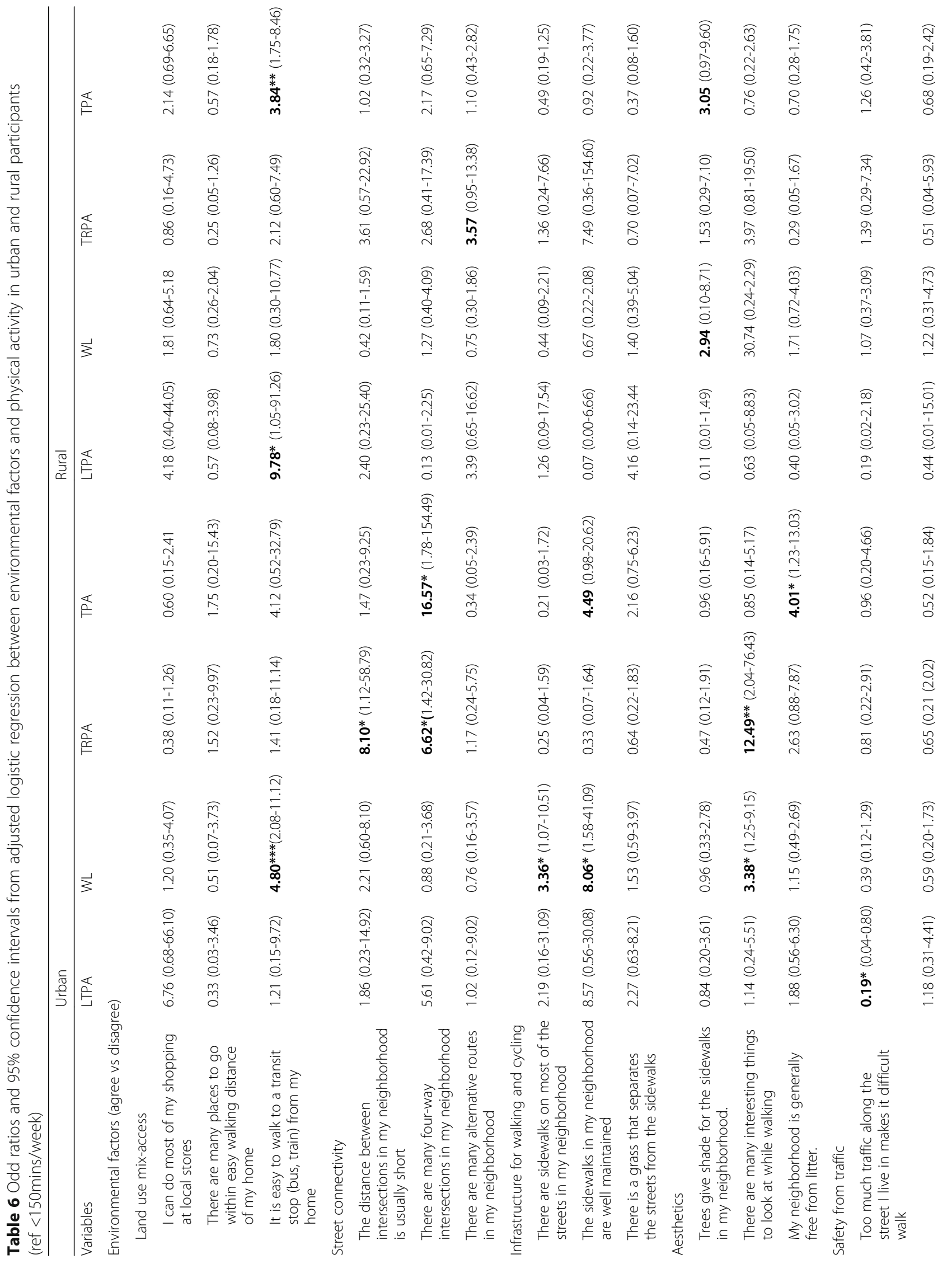




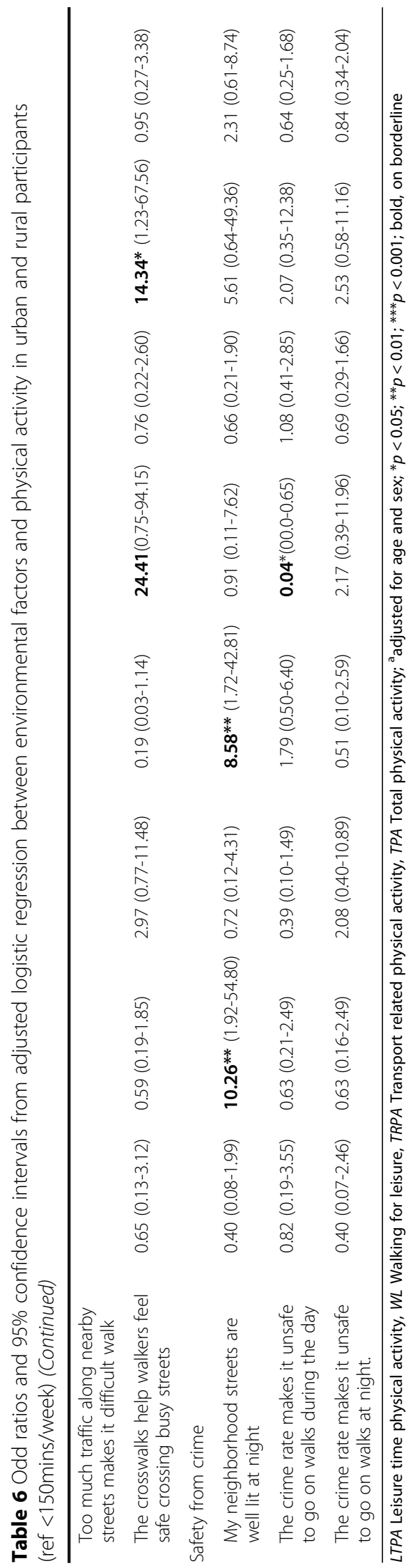


quality sidewalks have been associated with both walking and meeting physical activity recommendations elsewhere [28]. Here, neighborhoods with sidewalks on most streets were also associated with meeting 150 min per week or more of moderate-vigorous-physical activity [29]. In another study, lack of sidewalks was inversely associated with walking for leisure [30]. A possible explanation for these inconsistencies is that in some cities, sidewalks may serve more as a barrier than they do as a facilitator for walking. Sidewalks can be of poor quality and badly maintained and when combined with overcrowding, a person's ability to use them and the enjoyment of doing so is reduced [30].

Our participants who indicated seeing pleasant scenery (interesting things) while walking were more likely to reach $150 \mathrm{~min}$ per week or more of transport related physical activity, similar to the results in another study [19]. This implies that the good quality aesthetics in the neighborhood environment may positively influence the transport-related physical activity.

This study also noted that high volumes of traffic along the streets was associated with a lower likelihood of leisure-time physical activity and walking for leisure, which is similar to results found by studies in high-income countries [31]. For example, in the USA, neighborhoods that are safe from traffic were positively associated with walking [32]. Our results suggest that heavy traffic may be a barrier to physical activity and give preliminary evidence of the need to provide safe traffic environments to support physical activity in Africa.

Concerning crosswalks, this study observed that individuals who agreed that the crosswalks in their neighborhood helped walkers feeling safe crossing busy streets were also more likely to report sufficient levels of transportedrelated physical activity. Again, these results are consistent with those found in other studies [33]. Hence, having crosswalks in neighborhoods with high traffic volume may play an important role in determining the safety and physical activity levels of residents. The results of this study add to the existing, comparable literature by demonstrating that the association between crosswalks and physical activity meets public health recommendations for physical activity in urban and rural (African) settings.

Well-lit streets at night were positively associated with walking for leisure. These findings are significant in a South African context where crime rates are considered to be very high, and increasing with rapid urbanization. A study in the US found that feeling safe was linked to leisure time [33]. Similar results were reported in England [34] and Nigeria [11]. These pointedly demonstrate the need to assess perceived neighborhood attributes and their influence on physical activity [35]. However, limited information in the African context makes direct comparisons with other studies challenging. Perceived safety during the day is related to walking as most of individuals walk for transportation, especially among working class [11]. In addition, this relationship suggests that street lights could act as an indirect indicator for personal safety which in turn promotes walking for leisure as a choice rather than a need.

\section{Limitations and strengths of the study}

Our study has some limitations. It relies on self-reported physical activity and perceived environment, rather than objectively measured physical activity and perceived built environment. Recall bias and imprecise assessment of physical activity could dilute some of the observed associations. In addition, our study is also affected by common sources bias between two self-reported measures which inflate the magnitude of associations. Furthermore, due to the non-availability of cluster-level data, we were unable to account for the clustering effect in the analysis. This has the undesirable effect of generating too conservative standard error, and increasing the risk of type 1 errors. Strengths of this study include the use of both NEWS and IPAQ, which makes it comparable with other studies, globally. Furthermore, this study included a sample population from urban and rural areas that has geographical variability in a perceived built environment.

\section{Conclusion}

We found perceived built environment attributes to be associated with health related physical activity. Our findings provide baseline evidence for the need to provide walkable environments that will make it easier for South African adults to meet physical activity guidelines.

\section{Abbreviation}

IPAQ: International physical activity questionnaire; LTPA: Leisure time physical activity; NEWS: Neighborhood environmental walkability scale;

PURE: Prospective Urban and Rural Epidemiology; TPA: Total physical activity; TRPA: Transport related physical activity; WL: Walking for leisure

\section{Acknowledgements \\ The authors gratefully acknowledge the Population Health Research Institute, Hamilton Health Sciences and McMaster University, Hamilton, Canada and the Medical Research Council of South Africa for providing access to these data. Opinions, findings, conclusions and recommendations expressed are those of the authors and the funders accept no liability whatsoever in this regard.}

\section{Funding}

This study was supported by Social Innovation in Public Health Impulse fellowship program for analysis, interpretation of data, transport and accommodation.

\section{Availability of data and materials}

The data used for the current analysis form part of the global PURE study and are therefore not available for sharing in isolation from the global dataset. However, the data is available for use in collaboration with local investigators. Interested parties may contact Prof Thandi Puoane on tpuoane@uwc.ac.za. 


\section{Authors' contributions}

PM, APK, EVL, ADV and TP were involved in the conception and design. PM conducted the analysis and interpretation. PM, ADV and APK were involved with interpretation and wrote the first draft. All of the authors were involved with drafting and revising and final approval.

\section{Competing interests}

The authors declare that they have no competing interest.

\section{Consent for publication}

No applicable.

\section{Ethics approval and consent to participate}

The study was conducted according to the Helsinki principles [36]. The Senate Higher Degrees committee, Research Committees of the University of the Western Cape, South Africa and the Population Health Research Institute, Canada approved this study (Registration \#13/6/18). A consent form was signed by all the participants.

\section{Author details}

${ }^{1}$ Faculty of Community and Health Sciences School of Public Health, University of Western Cape, Cape Town, South Africa. ${ }^{2}$ Non-communicable Diseases Unit, South African Medical Research Council, Cape Town, South Africa. ${ }^{3}$ Division of Exercise Science and Sports Medicine, Department of Human Biology, Faculty of Health Sciences, University of Cape Town, Cape Town, South Africa.

\section{Received: 10 March 2016 Accepted: 13 February 2017}

Published online: 20 February 2017

\section{References}

1. Zwald ML, Hipp JA, Corseuil MW, Dondson EA. Correlates of walking for transportation and use of public transportation among adults in St Louis, Missouri, 2012. Prev Chronic Dis. 2014;11:140125. doi:10.5888/pcd11.140125.

2. McVeigh JA, Norris SA. Criterion validity and test-retest reliability of physical activity questionnaire in South African primary school-aged children. South African J Sport Med. 2012;24(2):43-8.

3. Joubert J, Norman R, Lambert EV, Groenewald P, Schneider M, Bull F, Bradshaw D. Estimating the burden of disease attributable to physical inactivity in South Africa in 2000. South African Med J. 2007;97:725-31

4. Department of Health, Medical Research Council, OrcMacro. South Africa Demographic and Health Survey 2003. Pretoria: Department of Health; 2007. http://www.mrc.ac.za.

5. de Sa E, Ardern Cl. Neighbourhood walkability, leisure-time and transportrelated physical activity in a mixed urban-rural area. Peer J. 2014;14:693. doi:10.1186/1471-2458-14-693.

6. Owen N, Humpel N, Leslie E, Bauman A, Sallis JF. Understanding environmental influences on walking; review and research agenda. Am J Prev Med. 2004:27:67-76

7. Wallmann B, Bucksch J, Froboese I. The association between physical activity and perceived environment in German adults. Eur J Public Health. 2012;22(4):502-8.

8. Jack E, McCormack GR. The associations between objectivelydetermined and self-reported urban form characteristics and neighborhood-based walking in adults. Int J Behav Nutr Phys Act. 2014; 11:71. doi:10.1186/1479-5868-11-71.

9. Su M, Tan Y-Y, Liu Q-M, Ren Y-J, Kawachi I, Li L-M, Lv J. Association between perceived urban built environment attributes and leisure-time physical activity among adults in Hangzhou, China. Prev Med. 2014:66:60-4.

10. Nieuwenhuijsen MJ. Urban and transport planning, environmental exposures and health-new concepts, methods and tools to improve health in cities. Environ Health. 2016;15 Suppl 1:38. doi:10.1186/s12940-016-0108-1.

11. Oyeyemi AL, Adegoke BO, Sallis JF, Oyeyemi AY, De Bourdeaudhuij I. Perceived crime and traffic safety is related to physical activity among adults in Nigeria. BMC Public Health. 2012;12(1):294.

12. Van Dyck D, Cerin E, Conway TL, De Bourdeaudhuij I, Owen N, Kerr J, Cardon G, Frank LD, Saelens BE, Sallis JF. Perceived neighborhood environmental attributes associated with adults' leisure-time physical activity : Findings from Belgium, Australia and the USA. Soc Sci Med. 2012;74:1375-84.

13. Teo K, Chow CK, Vaz M, Rangarajan S, Yusuf S. The Prospective Urban Rura Epidemiology [PURE] study : examining the impact of societal influences on chronic noncommunicable diseases in low-middle-and high-income countries. Am Heart J. 2009;185(1):1-7.

14. Bauman A, Bull F, Chey T, Craig CL, Ainsworth BE, Sallis JF, Bowles HR, Hagstromer M, Sjostrom M, Pratt M, The IPS Group. The international prevalence study on physical activity: results from 20 countries. Int J Behav Nutr Phys Act. 2009, doi:10.1186/1479-5868-6-21.

15. Adams MM, Ryan S, Kerr J, Sallis JF, Patrick K, Frank LD, Norman GJ. Validation of the Neighborhood Environment Walkability Scale (NEWS) items using Geographic Information Systems. J Phys Act Health. 2009;6 Suppl 1:S113-23.

16. Cleland V, Sodergren M, Otahal P, Timperio A, Ball K, Crawford D, Salmon J, McNaughton SA. Associations between the perceived environment and physical activity among adults aged 55-65 years : does urban-rural area of residence matter? J Aging Phys Act. 2015;23:55-63.

17. World Health Organisation. Global Recommendations on Physical Activity for Health. Geneva: WHO Press; 2010.

18. Craig $C L$, Mashall AL, Sjostrom M, Bauman AE, Booth ML, Ainsworth BE, Pratt M, Ekelund U, Yngve A, Sallis JF, Pekka OJA. International physical activity questionnaire: 12-country reliability and validity. Med Sci Sport Exerc. 2003; 35:1381-95.

19. Cerin E, Saelens BE, Sallis JF, Frank LD. Neighborhood Environment Walkability Scale: Validity and Development of a Short Form. Med Sci Sports Exerc. 2006;38(9):1682-91.

20. Schlomer GL, Bauman S, Card NA. Best practices for missing data management in counseling psychology. J Couns Psychol. 2010;57(1):1-10.

21. Saelens BE, Moudon AV, Kang B, Hurvitz PM, Zhou C. Relationship between higher physical activity and public transit use. Am J Public Health. 2014; 104(5):854-9.

22. Ding D, Adams MA, Sallis JF, Norman GJ, Hovell MF, Chambers CD, Hofstetter CR, Bowles HR, Hagströmer M, Craig CL, Gomez LF, Bourdeaudhuij ID, Macfarlane DJ, Ainsworth BE, Bergman P, Bull FC, Carr H, Klasson-Heggebo L, Inoue S, Murase N, Matsudo S, Matsudo V, McLean G, Sjöström M, Tomten H, Lefevre J, Volbekiene V, Bauman AE. Perceived neighborhood environment and physical activity in 11 countries: do associations differ by country? Int J Behav Nutr Phys Act. 2013;10:57. doi:10.1186/1479-5868-10-57.

23. Jia $Y$, Usagawa $T$, Fu $H$. The association between walking and perceived environment in Chinese Community Residents : a cross-sectional study. PLoS ONE. 2014;9(2):e90078. doi:10.1371/journal.pone.0090078.

24. Pikora TJ, Giles-Corti B, Knuiman MW, Bull FC, Jamrozik K, Donovan RJ. Neighborhood environmental factors correlated with walking near home: using SPACES. Med Sci Sports Exerc. 2006;38(4):708-14.

25. Shoham DA, Dugas LR, Bovet P, Forrester TE, Lambert EV, Plange-Rhule J, Schoeller DA, Brage S, Ekelund U, Durazo-Arvizu RA, Cooper RS, Luke A. Association of car ownership and physical activity across the spectrum of human development: Modeling the Epidemiologic Transition Study (METS). BMC Public Health. 2015;15:173. doi:10.1186/s12889-015-1435-9.

26. Oyeyemi AL, Adegoke BO, Oyeyemi AY, Sallis JF. Perceived environmental correlates of physical activity and walking in African young adults. Am J Heal Promot. 2011;25(5):10-20.

27. Lee C, Moudon AV. Correlates of walking for transportation or recreation purposes. J Phys Act Heal. 2006;3(1):77-98.

28. Addy C, Wilson D, Kirtland K, Ainsworth BE, Sharpe P, Kimsey D. Associations of perceived social and physical environmental supports with physical activity and walking behavior. Am J Public Health. 2004;94(3):440-3.

29. Sallis J, Bowles HRB, Bauman A. Neighborhood environments and physical activity among adults in 11 countries. Am J Prev Med. 2009;36(6):484-90.

30. Gomes GA, Reis RS, Parra DC, Ribeiro I, Hino AA, Hallal PC, Malta DC, Brownson RC. Walking for leisure among adults from three Brazilian cities and its association with perceived environment attributes and personal factors. Int J Behav Nutr Phys Act. 2011;8:111. doi:10.1186/1479-5868-8-111.

31. Kramer D, Maas J, Wingen M, Kunst AE. Neighbourhood safety and leisuretime physical activity among Dutch adults: a multilevel perspective. Int Behav Nutr Phys Act. 2013;10:11. doi:10.1186/1479-5868-10-11.

32. Wilson DK, Griffin SF, Ainsworth BE. Perceptions of environmental supports for physical activity in African American and white adults in a rural county in South Carolina. Prev Chronic Dis. 2005;2(4):1-10.

33. McGinn AP, Evenson KR, Herring AH, Huston $\mathrm{SL}$, Rodriguez DA. Exploring associations between physical activity and perceived and objective measures of the built environment. J Urban Heal 2007, 84(2). doi:10.1007/s11524-006-9136-4. 
34. Foster C, Hillsdon M, Thorogood M. Environmental perceptions and walking in English adults. J Epidemiol Community Heal. 2004;58(11):924-8.

35. Holahan CK, Velasquez KS, You X. Relationship of perceived environmental characteristics to leisure-time physical activity and meeting recommendations for physical activity in Texas. Prev Chronic Dis. 2009;6(1):A24. [Accessed: 03/07/2012]http://wwww.cdc.gov/pcd/ issues/2009/jan/08_0018.htm.

36. World Health Organisation. World Medical Association Declaration of Helsinki. Bull World Heal Organ. 2001;79(4):373-4.

Submit your next manuscript to BioMed Central and we will help you at every step:

- We accept pre-submission inquiries

- Our selector tool helps you to find the most relevant journal

- We provide round the clock customer support

- Convenient online submission

- Thorough peer review

- Inclusion in PubMed and all major indexing services

- Maximum visibility for your research

Submit your manuscript at www.biomedcentral.com/submit
Biomed Central 